University of Nebraska - Lincoln

DigitalCommons@University of Nebraska - Lincoln

Michigan Bovine Tuberculosis Bibliography and

Database

Wildlife Disease and Zoonotics

1999

\title{
Development of a Model of Natural Infection with Mycobacterium bovis in White-Tailed Deer
}

\author{
Mitchell V. Palmer \\ Zoonotic Diseases Research Unit, National Animal Disease Center, Agricultural Research Service, USDA, \\ Mitchell.Palmer@ars.usda.gov \\ Diana L. Whipple \\ Zoonotic Diseases Research Unit, National Animal Disease Center, Agricultural Research Service, USDA \\ Steven C. Olsen \\ Zoonotic Diseases Research Unit, National Animal Disease Center, Agricultural Research Service, USDA
}

Follow this and additional works at: https://digitalcommons.unl.edu/michbovinetb

Part of the Veterinary Medicine Commons

Palmer, Mitchell V.; Whipple, Diana L.; and Olsen, Steven C., "Development of a Model of Natural Infection with Mycobacterium bovis in White-Tailed Deer" (1999). Michigan Bovine Tuberculosis Bibliography and Database. 66.

https://digitalcommons.unl.edu/michbovinetb/66

This Article is brought to you for free and open access by the Wildlife Disease and Zoonotics at DigitalCommons@University of Nebraska - Lincoln. It has been accepted for inclusion in Michigan Bovine Tuberculosis Bibliography and Database by an authorized administrator of DigitalCommons@University of Nebraska Lincoln. 


\title{
DEVELOPMENT OF A MODEL OF NATURAL INFECTION WITH MYCOBACTERIUM BOVIS IN WHITE-TAILED DEER
}

\author{
Mitchell V. Palmer, ${ }^{1,2}$ Diana L. Whipple, ${ }^{1}$ and Steven C. Olsen ${ }^{1}$ \\ ${ }^{1}$ Zoonotic Diseases Research Unit, National Animal Disease Center, Agricultural Research Service, USDA, 2300 \\ Dayton Rd., Ames, lowa 50010 \\ 2 Corresponding author (e-mail: mpalmer@nadc.ars.usda.gov)
}

ABSTRACT: The objective of this study was to develop a suitable experimental model of natural Mycobacterium bovis infection in white-tailed deer (Odocoileus virginianus), describe the distribution and character of tuberculous lesions, and to examine possible routes of disease transmission. In October 1997, 10 mature female white-tailed deer were inoculated by intratonsilar instillation of $2 \times 10^{3}$ (low dose) or $2 \times 10^{5}$ (high dose) colony forming units (CFU) of M. bovis. In January 1998, deer were euthanatized, examined, and tissues were collected 84 to 87 days post inoculation. Possible routes of disease transmission were evaluated by culture of nasal, oral, tonsilar, and rectal swabs at various times during the study. Gross and microscopic lesions consistent with tuberculosis were most commonly seen in medial retropharyngeal lymph nodes and lung in both dosage groups. Other tissues containing tuberculous lesions included tonsil, trachea, liver, and kidney as well as lateral retropharyngeal, mandibular, parotid, tracheobronchial, mediastinal, hepatic, mesenteric, superficial cervical, and iliac lymph nodes. Mycobacterium bovis was isolated from tonsilar swabs from 8 of 9 deer from both dosage groups at least once 14 to 87 days after inoculation. Mycobacterium bovis was isolated from oral swabs 63 and 80 days after inoculation from one of three deer in the low dose group and none of four deer in the high dose group. Similarly, M. bovis was isolated from nasal swabs 80 and 85 days after inoculation in one of three deer from the low dose group and 63 and 80 days after inoculation from two of four deer in the high dose group. Intratonsilar inoculation with $M$. bovis results in lesions similar to those seen in naturally infected white-tailed deer; therefore, it represents a suitable model of natural infection. These results also indicate that $M$. bovis persists in tonsilar crypts for prolonged periods and can be shed in saliva and nasal secretions. These infected fluids represent a likely route of disease transmission to other animals or humans.

Key words: Mycobacterium bovis, Odocoileus virginianus, pathology, transmission, tuberculosis, white-tailed deer.

\section{INTRODUCTION}

Tuberculosis in free-ranging whitetailed deer (Odocoileus virginianus) was first recognized in the United States in 1934 when two wild white-tailed deer infected with Mycobacterium bovis were described as having pulmonary and thoracic lymph node lesions indistinguishable from those seen in cattle (Levine, 1934). It was suggested that cattle were the source of infection for these two wild deer, and that no reservoir of $M$. bovis infection existed in free-ranging white-tailed deer.

In 1994, a white-tailed deer in Alpena County (Michigan, USA) killed by a hunter, was found to have gross and microscopic lesions consistent with M. bovis (Schmitt et al., 1997). This prompted a survey in Michigan in 1995 and 1996 which resulted in isolation of $M$. bovis from 12 of 354 deer. As of 1 October 1998, over 8,800 deer from the affected area of Michigan have been tested and 151 (1.7\%) have been diagnosed as positive for $M$. bovis. With over 19 million white-tailed deer, 5 million mule and black-tailed deer (Odocoileus hemionus), and 750,000 wapiti (Cervus elaphus) in the continental United States (Hunter, 1996), a wild Cervidae reservoir of $M$. bovis would jeopardize the bovine tuberculosis eradication effort. Countries with wild animal reservoirs of M. bovis, such as New Zealand and Great Britain have been forced to adopt a bovine tuberculosis control effort rather than disease eradication.

To control or eradicate tuberculosis in cervids, a better understanding of the pathogenesis, transmission, and epidemiology will be critical. This study was designed to develop a suitable experimental model of natural $M$. bovis infection in 
white-tailed deer, describe the distribution and character of tuberculous lesions, and to examine possible routes of disease transmission to other deer, domestic livestock, and humans.

\section{MATERIALS AND METHODS}

Ten, mature, female, white-tailed deer were obtained from a private whitetail breeder in Alpena County (Michigan, USA; $44^{\circ} 52^{\prime} \mathrm{N}$, $83^{\circ} 51^{\prime} \mathrm{W}$ ) and moved to the National Animal Disease Center in Ames (Iowa, USA; $42^{\circ} 03^{\prime} \mathrm{N}$, $93^{\circ} 63^{\prime} \mathrm{W}$ ) in September 1997. Throughout the experiment (October 1997 to January 1998), deer were housed according to dosage group in pens separated by concrete walls in a biosecurity level III building. Direct contact was not possible between deer in different dosage groups. Negative control deer $(n=2)$ were maintained in a single pen in a separate building. Prior to inoculation, and 81 days after inoculation, all deer were tested for exposure to $M$. bovis by the comparative cervical test (CCT) for Cervidae as described in USDA, APHIS, VS guidelines (United States Department of Agriculture, 1997). Briefly, hair was clipped from two sites on the right side of the midcervical region and the skin thickness of each site was measured. One-tenth $\mathrm{ml}$ of $M$. avium purified protein derivative (PPD) (0.4 $\mathrm{mg} / \mathrm{ml}$ ) was injected intradermally in the uppermost site and $0.1 \mathrm{ml}$ of $M$. bovis PPD (1 $\mathrm{mg} / \mathrm{ml}$ ) was injected into the lower site. Injection sites were observed, palpated, and measured approximately 72 hours after injection. Results were interpreted by plotting measurements on a scattergram developed by USDA for interpretation of the CCT for Cervidae (United States Department of Agriculture, 1997). Results of the CCT were used to classify deer as negative, suspect, or reactor.

Deer were randomly assigned to one of three groups. The low dose group $(n=4)$ received $1 \times 10^{3}$ colony forming units (CFU) of $M$. bovis in $0.15 \mathrm{ml}$ sterile saline solution $(0.9 \% \mathrm{NaCl})$ instilled in each tonsilar crypt as described previously (Palmer et al., 1999), for a total dose of $2 \times 10^{3} \mathrm{CFU}$ of $M$. bovis per deer. The high dose group $(n=4)$ received $1 \times 10^{5} \mathrm{CFU}$ of $M$. bovis in sterile saline in each tonsilar crypt for a total dose of $2 \times 10^{5} \mathrm{CFU}$ of $\mathrm{M}$. bovis. Control deer received $0.15 \mathrm{ml}$ of sterile saline in each tonsilar crypt.

For inoculation and sampling, deer were anesthetized with a combination of xylazine (Mobay Corporation, Shawnee, Kansas, USA) ( $2 \mathrm{mg} / \mathrm{kg}$ of body weight) and ketamine (Fort Dodge Laboratories, Fort Dodge, Iowa, USA)
(6 mg/kg) injected intramuscularly. After sampling, the effects of xylazine were reversed with tolazoline (Lloyd Laboratories, Shanandoah, Iowa, USA) (4 mg/kg) injected IV.

The strain of $M$. bovis used was strain 9511328-1315, originally isolated from a freeranging tuberculous white-tailed deer killed by a hunter in Alpena County, Michigan in 1994. The isolate was incubated at $37 \mathrm{C}$ for $6 \mathrm{wk}$ on Middlebrook's 7 H9 liquid media with $10 \%$ oleic albumin dextrose citrate enrichment (Bacto Middlebrook OADC Enrichment, DIFCO Laboratories, Detroit, Michigan, USA). After incubation, the bacteria were harvested by centrifugation, and washed twice with $0.01 \mathrm{M}$ phosphate buffered saline (PBS) solution, $\mathrm{pH}$ 7.4. After resuspension in PBS solution, serial 10-fold dilutions were inoculated on Middlebrook $7 \mathrm{H} 10$ agar slants supplemented with OADC to determine the number of CFU. Inoculum was then frozen at $-80 \mathrm{C}$ for future use.

Tonsilar, nasal, oral, and rectal swabs were collected for bacteriologic culture before inoculation and $7,14,21,35,50,63,80$, and 84 87 days after inoculation. Nasal, oral, and rectal swabs for bacteriologic culture were collected using a $15 \mathrm{~cm}$ sterile cotton swab. Nasal swabs were obtained by inserting a separate swab in each nasal cavity to a depth of approximately $10 \mathrm{~cm}$. Oral swabs were collected by passing the cotton swab over the sublingual oral cavity. Tonsilar swabs for bacteriologic culture were obtained with the aid of a laryngoscope and a sterile $18 \mathrm{~cm}$ cytology brush (Puritan Medical Products, Guilford, Maine, USA.) attached to the end of a $53 \mathrm{~cm}$ insemination pipette. Swabs were rinsed thoroughly in $1.0 \mathrm{ml}$ PBS. One half of the sample $(0.5 \mathrm{ml})$ was added to $0.2 \%$ benzalkonium chloride solution (Zephiran chloride, concentrate 17\%, Sterling Drug Inc., New York, New York, USA) and let sit at room temperature for $15 \mathrm{~min}$. After decontamination with benzalkonium chloride, samples were centrifuged for $20 \mathrm{~min}$ at $2,000 \mathrm{rpm}$ and the supernatant decanted. To the sediment was added $0.5 \mathrm{ml}$ of Bacto egg yolk enrichment $50 \%$ (DIFCO Laboratories, Detroit, Michigan, USA). Samples of the sediment-egg yolk combination were inoculated onto separate agar slants containing Stonebrinks, Harrold's egg yolk media, M7H10, or M7H11 media. Inoculated agar slants were incubated at $37 \mathrm{C}$ for 8 wk.

Deer were euthanatized by IV injection of sodium pentobarbital (Sleepaway, Fort Dodge Laboratories, Fort Dodge, Iowa, USA). Specimens collected for bacteriologic culture included; tonsil, lung, liver, spleen, kidney, brain, mammary gland; and mandibular, parotid, me- 
TABLE 1. Isolation of Mycobacterium bovis from nasal, oral, and tonsilar swabs collected from experimentally infected white-tailed deer.

\begin{tabular}{|c|c|c|c|c|c|c|c|c|}
\hline \multirow{3}{*}{$\begin{array}{l}\text { Days after } \\
\text { inoculation }\end{array}$} & \multicolumn{8}{|c|}{ Deer number } \\
\hline & \multicolumn{4}{|c|}{ Low dose } & \multicolumn{4}{|c|}{ High dose } \\
\hline & 3 & 7 & 8 & 10 & 1 & 2 & 5 & 6 \\
\hline 7 & & & & & & & & \\
\hline 14 & $\mathrm{NA}^{\mathrm{a}}$ & & & & & & $\mathrm{T}$ & $\mathrm{T}$ \\
\hline 21 & NA & & & & & & $\mathrm{T}$ & \\
\hline 35 & NA & $\mathrm{T}^{\mathrm{b}}$ & $\mathrm{T}$ & & & $\mathrm{T}$ & $\mathrm{T}$ & \\
\hline 50 & NA & $\mathrm{T}$ & $\mathrm{T}$ & & & $\mathrm{T}$ & $\mathrm{T}$ & \\
\hline 63 & NA & $\mathrm{O}^{\mathrm{c}}$ & & & $\mathrm{N}^{\mathrm{d}}$ & & $\mathrm{T}$ & \\
\hline 80 & NA & $\mathrm{N}, \mathrm{T}, \mathrm{O}$ & & & $\mathrm{T}$ & $\mathrm{T}$ & $\mathrm{N}, \mathrm{T}$ & \\
\hline $84-87$ & NA & $\mathrm{N}, \mathrm{T}$ & & & & $\mathrm{T}$ & $\mathrm{T}$ & \\
\hline
\end{tabular}

a NA = not available, deer died of aspiration pneumonia associated with anesthesia 14 days after inoculation.

$\mathrm{b}_{\mathrm{T}}=$ M. bovis isolated from tonsilar swab.

${ }^{\mathrm{c}} \mathrm{O}=M$. bovis isolated from oral swab.

${ }^{\mathrm{d}} \mathrm{N}=M$. bovis isolated from nasal swab.

dial retropharyngeal, lateral retropharyngeal, superficial cervical, tracheobronchial, mediastinal, mesenteric, hepatic, iliac, supramammary, and prefemoral lymph nodes. Specimens for bacteriologic culture were placed individually in sterile bags and frozen at $-80 \mathrm{C}$ for approximately 2 wk before processing. Processing of specimens was done as described previously (Payeur et al., 1992). Results were considered positive if $M$. bovis was isolated.

Tissue samples for microscopic examination included those collected for bacteriologic culture and trachea and parietal pleura. Specimens were fixed in neutral buffered $10 \%$ formalin and processed by routine paraffin embedment techniques. Sections were cut 5 - $\mu \mathrm{m}$ thick, stained with hematoxylin and eosin (H\&E) and examined by light microscopy. Adjacent $5-\mu \mathrm{m}$ sections were cut from specimens with tuberculous lesions and stained by the Ziehl-Neelsen technique for acid fast bacteria (Sheehan and Hrapchak, 1980) and the Brown and Brenn modified method of Gram staining for bacteria (Sheehan and Hrapchak, 1980).

\section{RESULTS}

Prior to inoculation with M. bovis, all but two deer had delayed type hypersensitivity (DTH) reactions which were considered negative for exposure to M. bovis. Deer 8 and 10, from the low dose group, had DTH reactions which plotted in the suspect zone using the scattergram for the CCT in Cervidae. Eighty-one days after inoculation, all M. bovis-inoculated deer had reactions which were considered pos- itive for exposure to M. bovis. Additionally, control deer 9 had a reaction which was also considered positive for exposure to $M$. bovis. Control deer 4 remained negative for exposure to $M$. bovis as determined by the CCT.

Fourteen days after inoculation, deer 3 died of aspiration pneumonia associated with anesthesia. Therefore, results of swab specimens are not available beyond that point for deer 3 (Table 1). Mycobacterium bovis was isolated from tonsilar swabs as early as 14 days after inoculation in two deer from the high dose group, and 35 days after inoculation from two deer in the low dose group. In both groups, tonsilar swabs from at least one deer yielded $M$. bovis at the termination of the study. In addition to tonsilar swabs, oral swabs yielded M. bovis 63 and 80 days after inoculation from deer 7 of the low dose group. Mycobacterium bovis was not isolated from oral swabs from any deer in the high dose group. Swabs of the nasal cavity of deer 7 yielded $M$. bovis 80 and 87 days after inoculation, and from deer 1 and 5, in the high dose group, 63 and 80 days, respectively, after inoculation. At no time was $M$. bovis isolated from rectal swabs. Mycobacterium bovis was not isolated from nasal, oral, tonsilar or rectal swabs from control deer. 
TABLE 2. Distribution of gross and microscopic lesions consistent with tuberculosis, and isolation of $M$. bovis from intratonsilarly infected white-tailed deer.

\begin{tabular}{|c|c|c|c|c|c|c|c|c|}
\hline \multirow[b]{3}{*}{ Tissue } & \multicolumn{8}{|c|}{ Deer number } \\
\hline & \multicolumn{4}{|c|}{ Low dose group } & \multicolumn{4}{|c|}{ High dose group } \\
\hline & $3^{a}$ & 7 & 8 & 10 & 1 & 2 & 5 & 6 \\
\hline Tonsil & B & $\mathrm{M}, \mathrm{B}$ & $\mathrm{M}, \mathrm{B}$ & $\mathrm{B}$ & - & M, G & $\mathrm{M}, \mathrm{G}, \mathrm{B}$ & $\mathrm{M}, \mathrm{G}, \mathrm{B}$ \\
\hline Medial retropharyngeal $\mathrm{LN}^{\mathrm{b}}$ & B & $\mathrm{M}, \mathrm{G}, \mathrm{B}$ & $\mathrm{M}, \mathrm{G}$ & $\mathrm{M}, \mathrm{G}, \mathrm{B}$ & - & $\mathrm{M}, \mathrm{G}, \mathrm{B}$ & $\mathrm{M}, \mathrm{G}, \mathrm{B}$ & $\mathrm{M}, \mathrm{G}, \mathrm{B}$ \\
\hline Lateral retropharyngeal LN & - & $\mathrm{M}, \mathrm{G}, \mathrm{B}$ & - & - & - & - & $\mathrm{M}, \mathrm{B}$ & M \\
\hline Mandibular LN & - & $\mathrm{M}, \mathrm{B}$ & - & - & - & - & $\mathrm{M}, \mathrm{B}$ & - \\
\hline Parotid LN & - & $\mathrm{M}, \mathrm{B}$ & $\mathrm{B}$ & - & - & - & $\mathrm{M}, \mathrm{B}$ & - \\
\hline Tracheobronchial LN & - & $\mathrm{M}, \mathrm{G}, \mathrm{B}$ & - & - & - & - & $\mathrm{M}, \mathrm{G}, \mathrm{B}$ & - \\
\hline Mediastinal LN & - & $\mathrm{M}, \mathrm{G}, \mathrm{B}$ & & - & - & - & $M, G, B$ & - \\
\hline Lung & - & $\mathrm{M}, \mathrm{G}, \mathrm{B}$ & $\mathrm{M}, \mathrm{G}, \mathrm{B}$ & - & $\mathrm{M}, \mathrm{G}, \mathrm{B}$ & $\mathrm{M}, \mathrm{G}$ & $\mathrm{B}$ & - \\
\hline Parietal pleura ${ }^{\mathrm{c}}$ & - & M & - & - & - & - & - & - \\
\hline Trachea $^{\mathrm{c}}$ & - & M, G & - & - & - & - & $\mathrm{M}, \mathrm{G}$ & - \\
\hline Liver & - & $\mathrm{M}, \mathrm{G}, \mathrm{B}$ & - & - & - & - & $\mathrm{M}, \mathrm{G}, \mathrm{B}$ & - \\
\hline Spleen & - & - & - & - & - & - & B & - \\
\hline Hepatic LN & - & $\mathrm{M}, \mathrm{G}, \mathrm{B}$ & - & - & - & M & $\mathrm{M}, \mathrm{B}$ & - \\
\hline Mesenteric LN & - & $\mathrm{M}, \mathrm{G}, \mathrm{B}$ & $\mathrm{M}, \mathrm{B}$ & - & - & $\mathrm{M}, \mathrm{G}$ & $M, G, B$ & - \\
\hline Suprficial cervical LN & - & $\mathrm{M}, \mathrm{B}$ & - & - & - & - & - & B \\
\hline Iliac LN & - & $\mathrm{M}, \mathrm{B}$ & - & - & - & M & - & - \\
\hline Supramammary LN & - & - & - & - & - & M & - & - \\
\hline Prefemoral LN & - & B & - & - & - & - & - & - \\
\hline Kidney & - & $\mathrm{M}, \mathrm{G}, \mathrm{B}$ & - & - & - & - & - & - \\
\hline
\end{tabular}

a Deer died of aspiration pneumonia associated with anesthesia 14 days after inoculation.

b Lymph node.

${ }^{\mathrm{c}}$ Not processed for isolation of $M$. bovis. $\mathrm{M}=$ microscopic lesion(s) consistent with tuberculosis and acid fast bacteria seen. $\mathrm{G}=$ gross lesion $(\mathrm{s})$ consistent with tuberculosis seen. $\mathrm{B}=$ isolation of $\mathrm{M}$. bovis. $-=$ no gross or microscopic lesion consistent with tuberculosis and $M$. bovis not isolated.

Mycobacterium bovis was isolated from at least one tissue from all $M$. bovis-inoculated deer (Table 2). Most commonly infected sites included the medial retropharyngeal lymph nodes and tonsils. Deer 1 from the high dose group had M. bovis only within the lung, while deer 2 , also from the high dose group, had M. bovis only in the medial retropharyngeal lymph node. In contrast, deer 7 , from the low dose group, had M. bovis in every tissue sampled except the spleen, brain, mammary gland and supramammary lymph nodes. Similarly, deer 5, from the high dose group, had $M$. bovis in all tissues examined except kidney, brain, mammary gland, and superficial cervical, iliac, supramammary, and prefemoral lymph nodes. Mycobacterium bovis was not isolated from any mammary glands, supramammary lymph nodes, or brain. A mycobacteria isolated from tracheobronchial lymph nodes from control deer 9 was determined not be within the M. tuberculosis complex by DNA probe analysis (AccuProbe $\mathrm{My}$ cobacterium tuberculosis complex, GenProbe Inc., San Diego, California, USA.). Biochemical tests identified this isolate as M. gastri. Mycobacterium bovis was not isolated from any tissue from control deer.

All M. bovis-inoculated deer developed lesions consistent with tuberculosis (Table 2). Although severity of lesions differed between individual animals, there was no difference in severity between low and high dose groups. Pulmonary lesions consisted of multifocal subpleural to deep, white, firm granulomas which ranged in size from $3 \mathrm{~mm}$ to $2 \mathrm{~cm}$. Two patterns of pulmonary lesion distribution were noted. In deer 7, lesions were disseminated evenly throughout all lung lobes. In all other deer with pulmonary lesions, tuberculous 


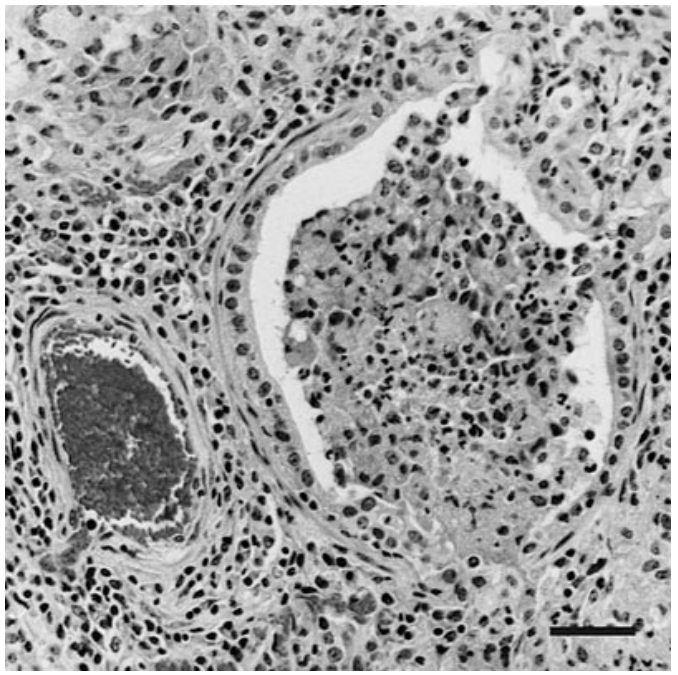

FIGURE 1. Section of lung from deer 7 inoculated intratonsilarly with $2 \times 10^{3} \mathrm{CFU}$ of $\mathrm{M}$. bovis. Macrophages and other inflammatory cells fill bronchiole lumen and surrounding alveolar spaces. H\&E. Bar = $55 \mu \mathrm{m}$.

lesions were most numerous in the caudal lung lobes.

Lymphadenopathy of the medial retropharyngeal lymph nodes was seen in three of four deer in the low dose group and three of four deer in the high dose group. Enlarged retropharyngeal lymph nodes were firm, and on cut surface contained multifocal areas of purulent material as well as caseous necrosis. Medial retropharyngeal lymph nodes of deer 2 were severely enlarged and on cut surface contained abundant green, tenacious, purulent material, surrounded by a region of caseous necrosis. Grossly visible tonsilar lesions were seen in three of four deer in the high dose group. Affected tonsils were moderately enlarged and firm. On cut surface, tonsils contained multifocal areas of purulent exudate.

Lesions were seen in the proximal tracheas of deer 6 and 7. Posterior to the larynx, the proximal 4 to $5 \mathrm{~cm}$ of tracheal mucosa was covered with a fibrinopurulent exudate. Removal of the exudate revealed hyperemic and necrotic tracheal mucosa. Liver from deer 5, and liver and kidney

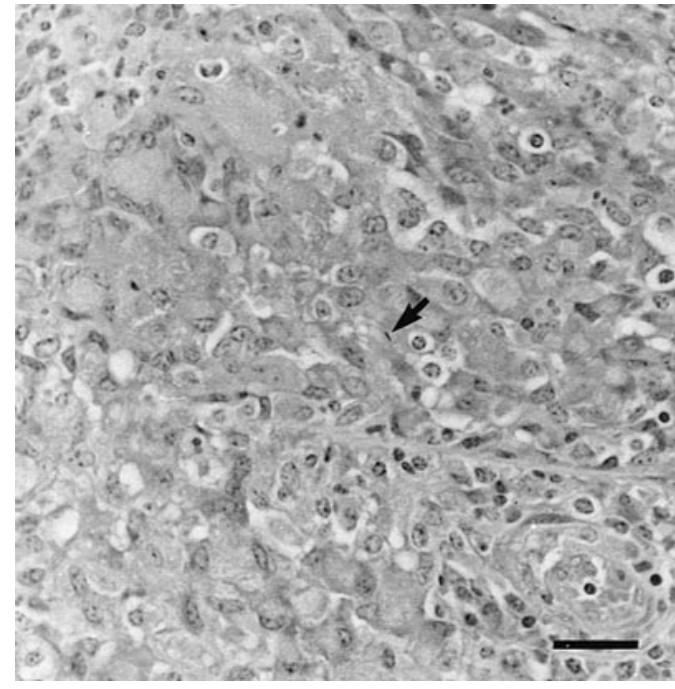

FIGURE 2. Section of lung from deer 7 inoculated intratonsilarly with $2 \times 10^{3} \mathrm{CFU}$ of $\mathrm{M}$. bovis. A single acid fast bacterium (arrow) is located within a macrophage. Macrophages and multinucleated giant cells fill bronchiolar lumen. Ziehl Neelsen. Bar $=35 \mu \mathrm{m}$.

from deer 7 contained capsular, white, nodular lesions, 3 to $10 \mathrm{~mm}$ in size.

Microscopic lesions consistent with tuberculosis were seen in all organs in which grossly visible tuberculous lesions were noted. Additionally, microscopic tuberculous lesions were seen in supramammary, iliac, superficial cervical, parotid, and mandibular lymph nodes, and parietal pleura (Table 2). Microscopically, tuberculous lesions were similar regardless of location and were composed of central areas of caseous necrosis surrounded by numerous epithelioid and vacuolated macrophages, lymphocytes, and multinucleated giant cells. Few neutrophils were seen within granulomas. Ziehl-Neelsen staining of granulomas revealed low to moderate numbers of acid fast bacilli that were located within epithelioid macrophages, multinucleated giant cells, or free within the necrotic caseum.

In sections of lung from deer 7 , alveolar and bronchiolar lumina were partially to completely filled with large vacuolated macrophages containing acid fast bacteria (Figs. 1, 2). Similarly, the proximal tracheal 


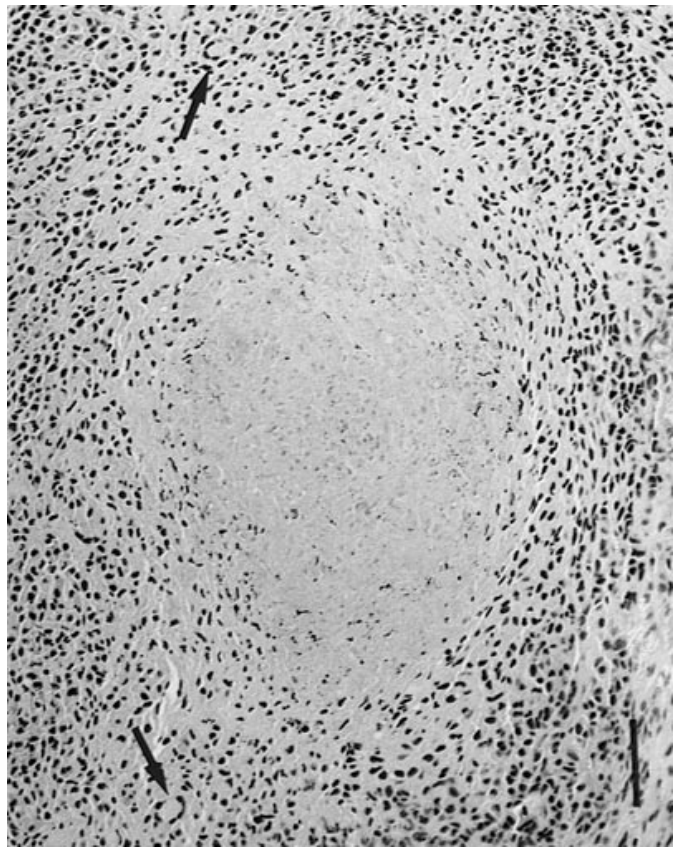

FIGURE 3. Section of trachea from deer 5 inoculated intratonsilarly with $2 \times 10^{5} \mathrm{CFU}$ of $M$. bovis. Submucosal granuloma composed of epithelioid macrophages and multinucleated giant cells (arrows). H/ E. Bar $=88 \mu \mathrm{m}$.

lesions from deer 7 and 5 were composed of multifocal to coalescing caseonecrotic granulomas which expanded the tracheal submucosa. Necrotic mucosa was covered by a thick layer of caseous debris which contained numerous acid fast bacteria (Figs. 3, 4). Luminally, caseous debris was covered by a thin layer of purulent exudate and necrotic debris which contained a mixture of numerous gram positive cocci, coccobacilli, and bacilli. Lesions consistent with tuberculosis were not seen in brain or mammary gland from M. bovis-inoculated deer nor in any tissue examined from control deer.

\section{DISCUSSION}

Intratonsilar inoculation of white-tailed deer with $M$. bovis represents a suitable model of natural infection. The distribution and character of lesions are similar to those reported for naturally infected white-tailed deer with lymph nodes of the

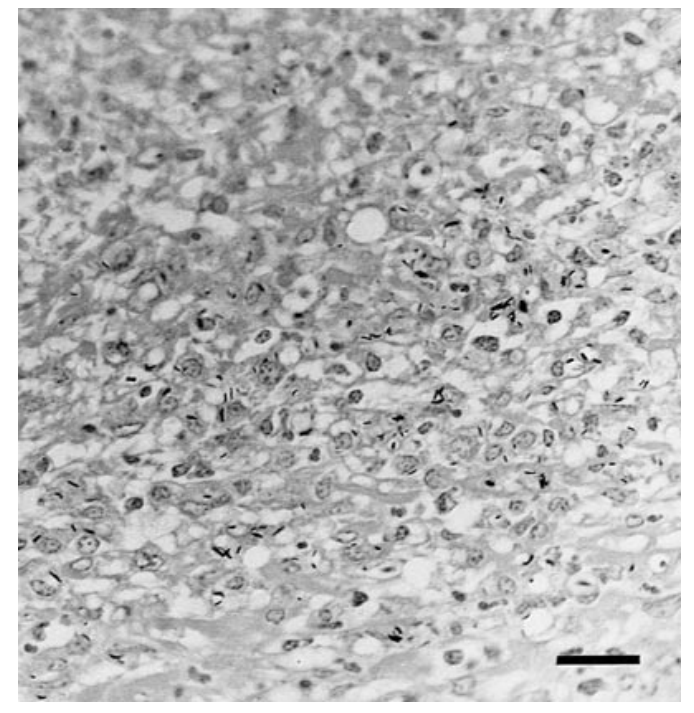

Figure 4. Section of trachea from deer 5 inoculated intratonsilarly with $2 \times 10^{5} \mathrm{CFU}$ of $\mathrm{M}$. bovis. Numerous acid fast bacteria in caseous exudate covering tracheal mucosa. Ziehl Neelsen. Bar $=35 \mu \mathrm{m}$.

head, thoracic cavity, and lungs being most commonly affected (Schmitt et al., 1997). Similar to our findings, a previous study of naturally infected white-tailed deer found the medial retropharyngeal lymph node to be the most commonly involved of all lymph nodes of the head or thorax (Schmitt et al., 1997). Involvement of the medial retropharyngeal lymph node is likely the result of lymph drainage from the tonsil. In other ruminant species efferent lymphatics from the tonsil drain directly to the medial retropharyngeal lymph node (Saar and Getty, 1975). Mycobacteria present in the oropharynx or mouth through inhalation or ingestion would be processed by the tonsil and likely carried through lymphatic vessels to the medial retropharyngeal lymph node.

Intratonsilar inoculation has been used previously to create models of natural tuberculosis in red deer (Cervus elaphus) (Mackintosh et al., 1995), and cattle (Palmer et al., 1999). In all cases, lesion distribution and character have been similar to those seen in naturally infected animals. Microscopic lesions in our whitetailed deer were similar in character to 
those seen in cattle. Variations seen in elk/ red deer and fallow deer (Dama dama) such as increased neutrophils and scattered peripheral mineralization were not seen (Rhyan et al., 1995).

Pulmonary airways containing mycobacteria-laden inflammatory cells in deer 7 , and tracheal exudate containing mycobacteria in deer 7 and 5 provide a likely source of $M$. bovis through aerosol as well as saliva and nasal secretions. The isolation of $M$. bovis from oral and nasal swabs from deer 7 is consistent with this route of transmission, moreover, contact with nasal mucus from infected animals has been shown to transmit $M$. bovis in cattle (Neill et al., 1989). Nose to nose contact or sharing of feeding sites may, therefore, facilitate deer to deer transmission. Supplemental feeding sites such as those described in northeastern Michigan (Schmitt et al., 1997) would serve to unnaturally increase deer density and increase the likelihood of contact with infected animals or feed contaminated with saliva or nasal mucus from infected animals. The results of this study suggest that in areas where $M$. bovis infection of white-tailed deer exist, management changes that decrease deer density or decrease contact between deer will decrease disease transmission.

Severe disseminated tuberculosis is not a prerequisite for the presence of $M$. bovis in saliva or nasal secretions. Deer $1 \mathrm{had}$ only pulmonary lesions with no visible involvement of tonsils or lymph nodes of the head, and isolation of $M$. bovis from only the lung; however, M. bovis was isolated from a nasal swab 63 days after inoculation. In experimentally infected cattle, $M$. bovis has been isolated from nasal secretions of cattle with mild involvement of the lung and/or thoracic lymph nodes (Neill et al., 1988). In one case, M. bovis was isolated from nasal secretions in the absence of gross or microscopic disease (Neill et al., 1988).

In our study, persistence of mycobacteria in tonsilar crypts differs from similar studies in cattle. One study using cattle in- oculated intratonsilarly with $M$. bovis failed to isolate $M$. bovis from tonsilar tissues as soon as 3 to $4 \mathrm{hr}$ or as long as 8 wks after inoculation (Palmer et al., 1999). This difference may be due to different host species, different strains of $M$. bovis, different pathogeneses, or different methods of sample collection for bacteriologic isolation. The significance of persistent tonsilar infection in white-tailed deer is unclear, however, persistent colonization of tonsilar crypts could play a key role in transmission through aerosol, saliva, or nasal secretions.

This study demonstrates that tuberculosis in white-tailed deer can become a disseminated disease with involvement of organs other than oropharyngeal or thoracic lymph nodes and lung within 90 days. Involvement of liver, kidney; and mesenteric, hepatic, supramammary, and iliac lymph nodes suggests that hematogenous as well as lymphatic dissemination does occur.

Suspect status after pre-inoculation skin testing of deer 8 and 10 may suggest prior exposure to M. bovis. However, false positive skin test results due to infection with nonpathogenic or saprophytic strains of mycobacteria occur in Cervidae (Kollias et al., 1982). No mycobacteria other than $M$. bovis were isolated from deer 8 or 10 . However, the positive skin test reaction of control deer 9 at the end of the study, and the isolation of $M$. gastri from tracheobronchial lymph nodes illustrate the problem of false positive intradermal skin test reactions in Cervidae. Other mycobacteria isolated from Cervidae that may confound skin test results include, M. avium, M. paratuberculosis, M. nonchromogenicum, M. diernhoferi, M. gastri, M. chelonei, M. smegmatis, M. vaccae, and other Runyon group III or IV mycobacteria (Kollias et al., 1982; de Lisle and Havill, 1985; Quigley et al., 1997).

\section{ACKNOWLEDGMENTS}

The authors thank R. Lyon for excellent technical assistance and K. Lies, J. Lies, L. Wright, D. Weuve, M. Knipper, and T. Krausman for outstanding animal care. 
Names are necessary to report factually on available data, however, the USDA neither guarantees nor warrants the standard of the product, and the use of the name by USDA implies no approval of the product to the exclusion of others that may also be suitable.

\section{LITERATURE CITED}

DELisle, G. W., AND P. F. Havill. 1985. Mycobacteria isolated from deer in New Zealand from 1970-1983. New Zealand Veterinary Journal 17: 138-140.

Hunter, D. L. 1996. Tuberculosis in free-ranging, semi free-ranging, and captive cervids. Revue Scientifique et technique de L'Office International des Epizooties 15: 171-181.

Kollias, G. V., C. O. Thoen, and M. E. Fowler. 1982. Evaluation of comparative cervical tuberculin skin testing in cervids naturally exposed to mycobacteria. Journal of the American Veterinary Medical Association 181: 1257-1262.

Levine, P. P. 1934. A report on tuberculosis in wild deer. Cornell Veterinarian 24: 264-266.

Mackintosh, C. J., K. Waldrup, R. Labes, G. BUCHAN, AND F. GRIFFIN. 1995. Intra-tonsil inoculation: An experimental model for tuberculosis in deer. In Otago Conference Series 3, Tuberculosis in wildlife and domestic animals, F. Griffin, and G. de Lisle (eds.). University of Otago Press, Dunedin, New Zealand, pp. 121-122.

Neill, S. D., J. Hanna, J. J. O'Brien, and R. M. MCCRACKEN. 1988. Excretion of Mycobacterium bovis by experimentally infected cattle. Veterinary Record 123: 340-343.

Neill, S. D., J. Hanna, J. J. O’Brien, and R. M. MCCRACKEN. 1989. Transmission of tuberculosis from experimentally infected cattle to in-contact calves. Veterinary Record 124: 269-271.

Palmer, M. V., D. L. Whipple, J. C. Rhyan, C. A. Bolin, AND D. A. SAARI. 1999. Granuloma development in cattle after intratonsilar inoculation with Mycobacterium bovis. American Journal of Veterinary Research 60: 310-315.

Payeur, J. B., J. L. Jarnagin, and J. G. MarQUARDT. 1992. Laboratory methods in veterinary mycobacteriology for the isolation and identification of mycobacteria. United States Department of Agriculture, Animal and Plant Health Inspection Service, National Veterinary Services Laboratories, Ames, Iowa, 141 pp.

Quigley, F. C., E. Costello, O. Flynn, A. GogarTy, J. MCGUirk, A. Murphy, AND J. Egan. 1997. Isolation of mycobacteria from lymph node lesions in deer. Veterinary Record 141: 516-518.

Rhyan, J. C., AND D. A. SAARI. 1995. A comparative study of the histopathologic features of bovine tuberculosis in cattle, fallow deer (Dama dama), Sika deer (Cervus nippon), and red deer and elk (Cervus elaphus). Veterinary Pathology 32: 215220.

SAAR, L. I., AND R. GETTY. 1975. Ruminant lymphatic system. In The anatomy of the domestic animals, 5th Edition, R. Getty (ed.). W. B. Saunders Company, Philadelphia, Pennsylvania, p. 1027.

Schmitt, S. M., S. D. Fitzgerald, T. M. Cooley, C. S. Bruning-Fann, L. Sullivan, D. Berry, T. Carlson, R. B. Minnis, J. B. Payeur, and J. SIKARSKIE. 1997. Bovine tuberculosis in freeranging white-tailed deer from Michigan. Journal of Wildlife Diseases 33: 749-758.

Sheehan, D. C., AND B. B. HrapchaK. 1980. Microorganisms. In Theory and practice of histotechnology. 2nd Edition. Mosby Publishing Co. St. Louis, Missouri, pp. 233-251.

United States Department of Agriculture. 1997. Animal and Plant Health Inspection Service, Veterinary Services. Bovine tuberculosis eradication uniform methods and rules. U.S. Government Printing Office, Washington, D.C., $21 \mathrm{pp}$.

Received for publication 22 September 1998. 